and successfully resisted. Perhaps later on some arsenical drug like salvarsan or neo-salvarsan will be found to have a beneficial effect in pneumococcal pneumonia or other pneumococcal infections, and it might be worth whils to undertake experiments with mice or rabbits in this comnexion-that is to say, one might try the effect of arsenical preparations, in regard to experimental pnermococcal pneumonia, in those animals.

\section{THREE CASES IN MIDWIFERY PRACTICE.}

\section{BX}

JOHN REID, B.A., M.D., B.CH., B.A.O., IATE SENIOR HOUSE-SCRGEON, SOJTH INFIRMARY, cors.

THE following unusual midwifery experiences occurred in my practice within four weeks, from the middle of March to the middle of April, 1912, and I think that as the material results are so good, and as one child born with asphyxia pallida recovered, it is worth while to publish the cases.

CASE I.-Rupture of Vterus with Extrusion of Intestines. This case I saw with my colleague Dr. Meade, of Ballymartle. The patient, who had had two difficult instrumental labours and two miscarriages, had been in bed for a couple of days, and for the last twenty-four hours was passing matter from the for the last twenty-four hours was passing matter from the vagina. She had also some abdominal pain. As she was but six months pregnant she did not suspect labour. Getting out of bed one morning at 10 o'clock to pass urine, the baby was ex-
pelled into the vessel. She got back into bed. On Dr. Meade's pelled into the vessel. She got back into bed. On Dr. Meade's arrival he found three coils of intestines hanging out of the vagina, as well as the cord. Having disinfected his hands and arm and the intestine, he returned the gut and at the same time turned out the placenta, which had been retained in the uterus. lermic injections of strychnine. I saw her next aftermoon, when she was vomiting severely and had well marked peritonitis. The pulse and temperature were high, and the tenderness over the abdomen extreme. The prognosis was most grave. On the third day a small piece of placenta was expelled. On the fifth day, when I saw her again, her conthree weeks was well on the road to recovery.

Her magnificent recovery was due to her own splendid constitution and the care taken of her by Dr. Meade, who had so carefully put back the intestines, and had adopted a semi-Fowler position, as well as gentle douching twice daily. She had hypodermic injections of strychnine twice a day, quinine and digitalis in pills thrice daily, and magnesium sulphate every third day. With the exception of the most gentle douching, no examination or manipulation of the genital passage was attempted, as we considered perfect rest of the parts gave her the best chance. What the condition was which allowed the intestines to protrude is difficult to tell. Probably she had an abscess in the posterior wall of the womb, low down, or else some collection of pus in Douglas's pouch, and the labour pains driving down the head of the child broke the walls of the sac, and so the intestines protruded. Of course, the child (which was under six months) died shortly after birth.

CASE II.-MIyelocele and Meningo-encephalocele.

This was a case of breech presentation, seen with Dr. Hennessy of Bandon. Chloroform was administered and the breech was extracted in the usual manner with extreme diffibreech was extracted in the usual manner with extreme diffi-
culty, owing to contracted pelvis. The arms were next extracted, culty, owing to contracted pelvis. The arms were nextextracted,
but it was wellnigh impossible to remove the head. We but it was wellnigh impossible to remove the head. We
noticed on the centre of the back a myelocele, and it was our noticed on the centre of the back a myelocele, and it was our
intention to cut across the neck with a scalpel and introduce a intention to cut across the neck with a scalpel and introduce a catheter into the cranium, as we considered it might be a case
of hydrocephalus. Whilst considering the advisability of doing this, and yet wishing, if possible, to extract a living child (as the only other one was stillborn), the head came away with a strong pull, and to our surprise showed an enormous ruptured meningo-encephalocele. Here was an example of both a myelocele and a meningo-eucephalocele. The uterus was thoroughly donched out with hot creolin solution, and the woman recovered in the usual time without any abnormality of temperature or pulse. I have arranged with her if she becomes pregnant again to have Caesarean section performed.

\section{CASE IIr.-Asphyxia Pallida.}

A primipara was seen by me after she had been in labour for thirty-six hours. I found membranes ruptured, heal presentation and prolapse of cord. I found afterwards a marginal insertion of an ordinary length of cord, and also that there was a history of curettage and wearing of a pessary for retroflexion, and a condition of sterility that had lasted for some years, so that there was probably some laxity of uterine muscle. The cord was pulsating and the fetal heart fairly strong. As the membranes were ruptured I considered the best chance for the child was rapid delivery, having warned the father that the child would undoubtedly be dead. With considerable difficulty I extracted by the aid of axis traction forceps, a male child, of normal size, in a condition of absolute asphy xia pallida. It was white and flaccid, and showed no attempt at respiration. I cleared the mouth of mucus, rubbed it with brandy, and tried artificial respiration by Schultze's method, and plunged it into hot and cold water. Finding these methods useless, I sterilized a plated oval female catheter, slightly curved, having five holes on either side, and hooking my left forefinger round the epiglottis, I gently passed the catheter into the child's trachea, and inflated the lungs, ten or twelve times a minute as near as I could judge. After fifteen minutes I could see the child's heart beating, and there was an occasional gasp; then the gasps became more frequent, and after three-quarters of an hom it was breathing well and quietly, but exceedingly weak in its cry. He is now a fine healthy boy, to the great joy of his father and mother.

In Holt's Discases of Infancy (p. 71) it is stated that inflation of the lungs is not usually of much general value, but is sometimes successful, and he recommends a soft catlieter or the laryngeal tube of Ribemont. I venture to think, however, that a sterilized metal catheter such as I have described, if inserted gently, will meet the conditions.

Some months previous to this case I used similar treatment in another case of asphyxia pallida, but without success. I could see the heart beating vigorously, and the child would give some gasps, then the heart got wealier, and finally, after keeping the heart going with the help of my assistant for an hour and a half, it gradually weakened, the gasps ceased, and death ensued.

As the cases of these two children seemed to me to be interesting from a physiological point of view, I wrote to Professor Halliburton (to whom my sincerest thanlss are due) as to why one child died and the other recovered. Since increasing venosity stimulates the respiratory centre we had here an excess of $\mathrm{CO}_{2}$; why, then, did my expired air, containing a large amount of $\mathrm{CO}_{2}$, produce a stimulation of the respiratory centre? Professor Halliburton's reply is as follows :

Your cases of asphyxia pallida are veryteresting. I imagine that in your second case the child was practically dead from deprivation of oxygen before you began the blowing in of air. The respiratory centre is very sensitive, and I would imagine that the few gasps you got were due to the oxygen supplied by Your own expired air, and not to the $\mathrm{CO}_{2}$ in your expired air. with $\mathrm{CO}_{2}$, and beyond a certain stage this gas is a poison. The with $\mathrm{CO}_{2}$, and beyond a certain stage this gas is a poison. The
pallor would be due to stoppage of the circulation and conpallor would be due to stoppage of the circulation and con-
stricted blood vessels; hence no bluewess. But I suspect the stricted blood vessels; hence no bluewess. But I suspect the
blood was very venous nevertheless, and I cannot therefore blood was very venous nevertheless, and I camnot therefore
think that any acapnia was present. In the first case the think that any acapnia was present. In the first case the
recovery due to oxygen supply was accomplished because the child to start with was only say 75 per cent. and not 99 per cent. dead.

The explanation given by Professor Halliburton is a great help, and it is a great incentive to know the reason why one is doing a certain action, and shows that by keeping up the treatment for a considerable time valuablo infant lives might be saved. No stillborn child should ever be condemned to its grave without this method being effectually carried out, for assuredly success will many times fo!low

THE report presented to the annual meeting of tho Royal Bath Hospital and Rawson Convalescent Home; Harrogate, on January 30th, announced the resignation of Dr. Chatles Gibson, who for twenty-one years had been an honorary medical officer to the hospital, and during that period had rendered it incalculable services. In moving the adoption of the report Major Dent, the chairman, observed among other things that it would be secn that very few subscriptions had been withdrawn owing to the National Insurance Act, and he hoped in connexion with institutions like that there would be no falling off. Whatever happened in other institutions the Insurance Act did not affect an institution like theirs, and it was essential that charitably disposed people and workpeople should continue liberally to support it. Certain alterations were made in the rules, and Dr. Hobson and Dr. Gibson were appointed honorary consultins physicians, Dr. Hinsley Walker and Dr. Johns were ap)pointed honorary medical officers, and Dr. G. L. Kerr Pringle and Dr. David Brown were added to the honorary medical staff. 